\title{
Effect of Statins on Early and Late Clinical Outcomes of Carotid Endarterectomy and the Rate of Post-Carotid Endarterectomy Restenosis
}

\author{
Ali F AbuRahma, MD, FACS, Mohit Srivastava, MD, Patrick A Stone, MD, FACS, Bryan K \\ Richmond, MD, MBA, FACS, Zachary AbuRahma, DO, Will Jackson, DO, L Scott Dean, \\ PhD, MBA, and Albeir Y Mousa, MD, FACS \\ Department of Surgery, West Virginia University (A AbuRahma, Srivastava, Stone, Richmond, Z \\ AbuRahma, Jackson, Mousa) and the CAMC Health Education and Research Institute (Dean), \\ Charleston, WV.
}

\section{Abstract}

BACKGROUND-This study analyzed the effect of statins on clinical outcomes after carotid endarterectomy (CEA) and the rate of restenosis.

STUDY DESIGN-We performed a retrospective analysis of prospectively collected data on 500 consecutive CEAs followed at 1, 6, and 12 months and every year.

\begin{abstract}
RESULTS-There were 299 patients on statins vs 201 without. Combined perioperative MI/ death rates were $2.7 \%$ vs $4 \%(\mathrm{p}=0.416)$ and $\mathrm{MI} / \mathrm{stroke} / \mathrm{death}$ rates were $4 \%$ vs $5 \%(\mathrm{p}=0.607)$ for statins vs no statins. At mean follow-up (27 months), MI, stroke, and death rates were: $9.7 \%$, $2.3 \%$, and $2.3 \%$ vs $9 \%, 2.5 \%$ and $4.5 \%(\mathrm{p}=0.18)$ for statins vs no statins, respectively. Diabetic patients not on statins had 4 times more deaths $(8.5 \%$ vs $2.3 \%)$ and twice as many strokes/deaths $(10.2 \%$ vs $5.3 \%)$. Patients with hypercholesterolemia who were not on statins had twice as many deaths $(4.3 \%$ vs $2.2 \%)$. Rates of freedom from stroke/MI/death at 1, 2, 3, and 4 years were: $94 \%$, $90 \%, 85 \%$ and $77 \%$ vs $94 \%, 89 \%, 85 \%$, and $82 \%$ ( $\mathrm{p}=0.87$ ) for statins vs no statins, respectively. Rates of freedom from death only for patients on statins vs no statins at 1, 2, 3, and 4 years were: $98 \%, 98 \%, 97.4 \%$ and $97.4 \%$ vs $98 \%, 96 \%, 94.8 \%$ and $94.8 \%$, respectively $(\mathrm{p}=0.191)$. For diabetic patients, rates of freedom from death at 1, 2, 3, and 4 years were $99 \%, 99 \%, 97 \%$, and $97 \%$ for statins vs $97 \%, 90 \%, 90 \%$, and $90 \%$ without statins, respectively $(\mathrm{p}=0.048)$. Post-CEA restenosis rates $250 \%$ were not significantly different between statins vs no statins $(\mathrm{p}=0.64)$.
\end{abstract}

Correspondence address: Ali F AbuRahma, MD, FACS, Department of Surgery, West Virginia University, 3110 MacCorkle Ave, SE, Charleston, WV 25304. ali.aburahma@camc.org.

Author Contributions

Study conception and design: A AbuRahma, Dean

Acquisition of data: Srivastava, Stone, Z AbuRahma. Jackson, Mousa

Analysis and interpretation of data: A AbuRahma, Dean

Drafting of manuscript: A AbuRahma, Richmond, Mousa

Disclosure Information: Authors have nothing to disclose. Timothy J Eberlein, Editor-in-Chief, has nothing to disclose.

Presented at the Southern Surgical Association 126th Annual Meeting, Palm Beach, FL, November 30-December 3, 2014. 
CONCLUSIONS-Statins significantly lowered death rates in patients with diabetes and tended to lower both death and stroke rates in diabetic patients and patients with hypercholesterolemia. Statins had no effect on post-CEA restenosis.

The pleiotropic effects of statins on the vascular system have resulted in several studies examining their use in several cardiovascular disorders such as coronary artery disease, peripheral artery disease, aneurysmal disease, stroke, and, more recently, in patients undergoing carotid endarterectomy (CEA). ${ }^{1-8}$

The Heart Protection Study (HPS) randomized patients into simvastatin $(40 \mathrm{mg})$ vs placebo and concluded that patients on statin therapy with a previous history of cerebrovascular events conferred a $24 \%$ risk reduction in the composite endpoint of myocardial infarction (MI), stroke, vascular death, and the need for revascularization. ${ }^{8}$ However, the incidence of late stroke alone was not reduced by statins, which was thought to be explained by the fact that patients probably gained more benefit from cardiac protection. Statins have also been shown to prevent stroke in clinical trials in different settings ${ }^{2}$ and have been associated with a reduction in adverse events in noncardiac surgery. Others have reported that statins have putative neurologic protective effects ${ }^{8}$; therefore, statins have been recommended for cardiovascular risk modification in many medical and surgical patients. However, only a few studies have reported on their benefits in patients undergoing CEA. This study analyzed the effects of statins on perioperative and late clinical outcomes after CEA and the rate of post-CEA restenosis.

\section{METHODS}

This is a retrospective analysis of data collected prospectively on 500 consecutive patients who had CEAs over a recent 3-year period performed by vascular surgeons at the Vascular Center of Excellence at Charleston Area Medical Center/West Virginia University, Charleston, WV. The data were collected from the electronic medical records, including operative procedures, perioperative notes, and routine follow-up notes at the Vascular Center of Excellence. Additional data were sought from family physicians, if necessary, in regard to reports related to major adverse events (stroke, MI, and/or death). The death data were also supplemented by checking the Social Security Death Index. This study was approved by the Institutional Review Board of West Virginia University/Charleston Area Medical Center, Charleston, WV.

Patient demographics and clinical characteristics were recorded, including age, sex, hypertension, diabetes mellitus, coronary artery disease, hypercholesterolemia, smoking, COPD, and chronic renal insufficiency. The indications for CEA were also recorded, whether symptomatic (transient ischemic attack [TIA] or stroke) or asymptomatic. Redo CEAs, CEAs combined with coronary artery bypass, or CEAs associated with other brachiocephalic reconstructions were excluded from analysis. Patients were classified according to statin use at the time of admission to the hospital for the procedure. Statin use was defined as any type of statin therapy at any dosage. It was presumed that each statin would have an equal effect on the outcome; therefore, all statin users were counted as a single variable for the sake of analysis. Patients were not assessed for medication adherence 
at any point and there was no attempt to collect data on the dosage, perioperative duration of treatment, or potential complications of statin use. However, all patients who were on preoperative statin therapy were continued on statins postoperatively at discharge.

All CEAs were done under general anesthesia with systemic heparin, routine carotid patching, and intraluminal shunting. They were given preoperative aspirin $(325 \mathrm{mg}$ or $81 \mathrm{mg}$ daily) within a few days of surgery, and it was continued indefinitely postoperatively.

Both 30-day perioperative and late major adverse events were recorded and analyzed, including stroke, MI, and/or death. These adverse events were compared between patients who were on statins vs no statins. Major adverse events, specifically death, were also compared in patients with diabetes mellitus and hypercholesterolemia, according to their intake of statins. All strokes were confirmed using brain CT scanning or MRI, and these patients were evaluated by a neurologist. An MI was defined as the presence of an abnormal electrocardiogram associated with chest pain and/or elevated plasma troponin with a value above $99 \%$ of the upper reference limit.

\section{Definition of comorbidities}

Coronary artery disease was defined as a history of angina, MI, coronary artery bypass graft, or coronary percutaneous transluminal angioplasty or stenting. Hypertension was defined as medical treatment for hypertension or consistent blood pressure of $>150 \mathrm{mmHg}$ systolic or $>90 \mathrm{mmHg}$ diastolic. Diabetes mellitus was defined as a history of medical treatment for diabetes.

The definition of COPD was the routine use of inhalers or a previous diagnosis of obstructive pulmonary disease or medical therapy for COPD. Chronic renal insufficiency/ end-stage renal disease was defined as renal failure requiring chronic renal replacement therapy. Hyperlipidemia was defined as the need for medical treatment for hyperlipidemia or total cholesterol above $200 \mathrm{mg} / \mathrm{dL}$.

Regarding post-CEA carotid duplex surveillance protocol, all patients underwent immediate postoperative duplex ultrasound, which was repeated at 1, 6, and 12 months, and every year thereafter. The presence of $\geq 50 \%$ and $\geq 80 \%$ post-CEA restenosis was analyzed for patients on statins vs no statins, using previously validated criteria in our accredited vascular laboratory. 9

\section{Statistical analysis}

A statistical analysis was performed using SAS 9.2 software. Categorical variables were analyzed using a contingency table with chi-square or Fisher's exact test to determine statistical significance. A Kaplan-Meier analysis was used to estimate survival for patients on statins vs no statins, and a similar analysis was done on patients with diabetes mellitus and hypercholesterolemia who were on statins vs no statins. 


\section{RESULTS}

This is a series of 500 consecutive CEAs: 299 patients on statins and 201 patients without statins. As noted in Table 1, all demographic and clinical characteristics were comparable, except the incidence of diabetes mellitus (44\% in the statin group vs $29 \%$ in the no statin group, $\mathrm{p}=0.001)$ and hypercholesterolemia $(76 \%$ vs $58 \%, \mathrm{p}<0.0001)$. The mean age for the group was 68.5 years (range 43 to 98 years). There were no statistically significant differences between the mean ages of patients on statins vs no statins (68.7 vs 68.1 years).

\section{Perioperative outcomes}

Table 2 summarizes the perioperative outcomes for patients on statins vs no statins. As noted, there were no significant differences in early perioperative outcomes: major adverse events (specifically MI, stroke, and death); combined perioperative stroke and death; MI and death; or MI, stroke, and death. As noted, statins tended to lower perioperative death rates, and perioperative MI and death rates by one-third.

\section{Late outcomes}

As noted in Table 2, at a mean follow-up of 27.4 months (range 1 to 68 months), there were no significant differences between the combined early and late stroke rates ( $2.3 \%$ vs $2.5 \%)$, MI $(9.7 \%$ vs $9 \%)$, death $(2.3 \%$ vs $4.5 \%, \mathrm{p}=0.1832)$, combined stroke and death $(4.3 \%$ vs $6 \%$ ), MI and death (11.7\% vs $12.4 \%$ ) and combined stroke, MI, and death (13.4\% vs $13.4 \%$ ) for patients on statins vs no statins. However, it should be noted that the combined stroke and death rates were cut by one-third and the combined early and late deaths were cut by one-half for patients on statins vs no statins.

\section{Combined early and late outcomes for diabetic patients and patients with hypercholesterolemia}

The combined early and late clinical outcomes are summarized for diabetic patients in Table 3 and for patients with hypercholesterolemia in Table 4. A subset analysis showed that diabetic patients not on statins had 4 times more deaths than diabetic patients on statins $(8.5 \%$ vs $2.3 \%, p=0.1101)$ and twice as many combined strokes and deaths $(10.2 \%$ vs $5.3 \%, \mathrm{p}=0.229$ ). Similarly, patients with hypercholesterolemia who were not on statins had twice as many deaths ( $4.3 \%$ vs $2.2 \%)$.

\section{Kaplan-Meier analysis of major adverse events}

Rates of freedom from stroke, MI, and death at 1, 2, 3, and 4 years were: 94\%, 91\%, 85\%, and $77 \%$ vs $94 \%, 89 \%, 85 \%$, and $82 \%(\mathrm{p}=0.87)$ for patients on statins vs no statins, respectively (Fig. 1). The rates of freedom from death (survival) for all patients at 1, 2, 3, and 4 years were $98 \%, 96 \%, 95 \%$, and $95 \%$ for patients without statins vs $98 \%, 98 \%, 97 \%$, and $97 \%$ for patients on statins, respectively ( $p=0.191$, Fig. 2 ). The rates of freedom from death in diabetic patients are shown in Figure 3: 99\%, 99\%, 97\%, and 97\% for diabetic patients on statins vs $97 \%, 90 \%, 90 \%$, and $90 \%$ for diabetic patients without statins at 1,2, 3 , and 4 years, respectively. As noted, there were statistically significant differences in survival rates in diabetic patients between those who were on statins vs no statins $(\mathrm{p}=$ 0.048). 


\section{Effect of statins on the rate of post-carotid endarterectomy restenosis}

Overall, 442 of 500 patients had available duplex ultrasounds beyond 6 months (in addition to their postoperative duplex ultrasound), and these were available for analysis of post-CEA restenosis. Post-CEA restenosis $250 \%$ was not significantly different between the 2 groups: 10 of $269(3.7 \%)$ vs 5 of $173(2.9 \%, \mathrm{p}=0.64)$, respectively, for patients on statins vs no statins.

\section{DISCUSSION}

Since their introduction in 1987, statins have become the preferred agents for treatment of hypercholesterolemia. ${ }^{5}$ Randomized clinical trials have conclusively demonstrated that statin use is correlated with a decrease in adverse cardiovascular events, with improved overall survival. ${ }^{5-8,10}$ In addition, the use of statins has been correlated with an antiinflammatory effect, slowing progression of atherosclerosis, plaque stabilization, inhibition of the development of intimal hyperplasia, and even a reduction in the size of atheromatous plaques over time. ${ }^{5,11,12}$ As a result, many patients with peripheral vascular disease are placed on statins, both for the lipid lowering effects of the drug and its above-mentioned pleiotropic effects. ${ }^{13}$ The effects of periprocedural statin administration have been studied in the treatment of coronary artery disease and acute coronary syndrome, but the results have been inconsistent, with some studies demonstrating reduced perioperative and late mortality, ${ }^{14}$ while others show no significant benefit of statin administration. ${ }^{15,16}$

Recently published literature has demonstrated that the perioperative use of statins in patients undergoing major vascular surgery is associated with reductions in both 30-day and 5-year mortality, ${ }^{17-19}$ as well as a reduction in major adverse cardiovascular events. ${ }^{20} \mathrm{In}$ addition, the perioperative administration of statins has also been associated with improved limb-related outcomes in patients with critical limb ischemia, although these results have not been consistent across all studies, with some demonstrating improvement in amputation-free survival $^{20-22}$ and others demonstrating no significant benefit with respect to limb-related outcomes. ${ }^{23,24}$ A 2013 Cochrane systematic review examined the role of statin administration and its effect on patients undergoing noncardiac vascular surgery. The authors concluded that, of the high-quality studies available for review, there were insufficient data to conclude that statin use was beneficial and further studies on this practice would be of value. ${ }^{25}$ However, the strict criteria for study inclusion used by the authors of the Cochrane review resulted in this being a rather limited analysis involving a small number of patients.

The few previously published studies on the role of statin therapy in the treatment of patients undergoing CEA suggest that statins may be of benefit in this subpopulation of vascular patients. A 10-year study (1994 to 2004) by the Johns Hopkins group ${ }^{5}$ of 1,440 patients undergoing isolated CEA demonstrated that the use of statins in CEA patients resulted in significant reductions in perioperative stroke $(1.2 \%$ vs $4.5 \%, \mathrm{p}<0.01)$ and mortality $(0.3 \%$ vs $2.1 \%, \mathrm{p}<0.01)$. A reduction in perioperative cardiac events was also observed $(1.2 \%$ vs $2.1 \%, \mathrm{p}=0.191)$; it trended toward, but ultimately failed to reach statistical significance. ${ }^{26}$ 
Another large 2005 study by LaMuraglia and associates ${ }^{27}$ demonstrated that statin use was beneficial in CEA patients, specifically in respect to CEA durability. A 10-year review (1989 to 1999) of 2,127 CEAs (only 50\% had patching) demonstrated that statin use was associated with improved durability of CEA. Specifically, a multivariate analysis showed a lower incidence of both early restenosis (odds ratio [OR] 0.601, p < 0.007) and late CEA anatomic failure (OR 0.128, $\mathrm{p}<0.003$ ), as well as a higher likelihood of late freedom from disease progression in patients receiving statins (OR 0.202, $\mathrm{p}<0.002) .{ }^{27}$ It should be noted that one-half of their patients didn't have carotid patching.

Finally, another 2005 study examined outcomes in 2,031 symptomatic CEA patients (815 on statins) and 1,252 asymptomatic patients (665 on statins) and found that the indication for CEA (symptomatic vs asymptomatic stenosis) may also play a role in the observed benefit of perioperative statin therapy. In their study, which used propensity score matching to control for differences in patient population characteristics, a benefit of statin administration was observed in symptomatic patients, with significant reductions in in-hospital mortality (OR 0.25, 95\% CI 0.07 to 0.90) and in-hospital ischemic stroke (OR 0.55, 95\% CI 0.32 to 0.95). However, this benefit was not observed when the indication for CEA was asymptomatic stenosis. ${ }^{2}$ Despite the retrospective and observational nature of these studies, the observed benefits have caused some vascular surgeons to recommend routine administration of statins to patients undergoing CEA. ${ }^{28}$

\section{Our experience}

In our study of 500 demographically similar CEA patients, statin administration did not significantly affect the rates of perioperative stroke, MI, or death, either when examined as independent variables or when studied in combination. The same phenomenon was observed with late outcomes; although the death rate was reduced by nearly $50 \%$ ( $4.5 \%$ in the no statin group vs $2.3 \%$ in the statin group, $\mathrm{p}=0.1832$ ). The failure of these trends to reach a level of statistical significance was most likely due to the low perioperative stroke/death rate (around 2\%) and the small number of patients who died during the study period (16 of 500). We believe that such an impressive trend in reduction certainly suggests the need to further study the effect of statin therapy on late mortality in this clinical setting.

When both early and late outcomes in specific subpopulations were considered, such as patients with diabetes mellitus and hypercholesterolemia, the results were even more impressive. Diabetic patients who were receiving statins were only $25 \%$ as likely to die in the follow-up period $(8.5 \%$ vs $2.3 \%, \mathrm{p}=0.1101)$ and nearly $50 \%$ less likely to suffer combined stroke/death $(10.2 \%$ vs $5.3 \%, \mathrm{p}=0.229)$ when compared with the no statin group. The failure of these impressive trends to reach significance was, once again, likely due to the relatively small number of patients suffering death or combined stroke/death during the study period. The Kaplan-Meier analysis of the 4-year freedom from death in diabetic patients demonstrated a significant benefit to statin use when compared with the no statin group $(\mathrm{p}=0.048)$.

In the hypercholesterolemia group, similar trends were observed with statin use in regard to a reduction in early and late deaths $(4.3 \%$ vs $2.2 \%, \mathrm{p}=0.3144)$, and $\mathrm{MI}(12.1 \%$ vs $8.8 \%, \mathrm{p}=$ 
0.3327). Although noteworthy, the small numbers did not allow these trends to reach a level of statistical significance.

Finally, statins did not significantly affect the rates of restenosis in our series; however, this finding was not unusual because restenosis rates are low after CEA across all populations with routine patch closure. ${ }^{29-31}$

The limitations of this study include its retrospective and observational design. Because of this study design, it was impossible to determine the duration of time patients had been on statins and the degree of lipid-lowering benefit in this subpopulation of patients. In addition, all statins were evaluated as a single group (any statin vs no statin), so we were unable to determine if different statins were more effective than others in regard to perioperative outcomes. Patient compliance with statin administration could not be evaluated objectively and, therefore, could be a confounding variable if the statin group was noncompliant with their prescribed regimen. Finally, although the sample size of 500 patients is by no means small, the number of observed adverse events was small and may have played a role in the failure of these impressive trends to reach significance.

These questions represent important areas for future study. Although a randomized controlled trial would certainly serve as the most definitive way to investigate the role of statins in CEA patients from a scientific perspective, the ethical considerations may ultimately prohibit such a trial from ever occurring. This is due to the well-established benefit of statins in reducing cardiovascular events and cardiovascular mortality in the atrisk population. ${ }^{5}$ Because these data are so well established, and the existence of these comorbidities are so prevalent in the vascular patient population, it would seem unethical to withhold statins to investigate the effect of statin administration on noncardiac interventions because this practice would subject the "no statin arm" to unnecessary risk.

\section{CONCLUSIONS}

In conclusion, patients who were placed on statin therapy after CEA tended to have lower death rates, but not stroke rates. However, statins significantly lowered death rates in diabetic patients and tended to lower both death and stroke rates in patients with diabetes and patients with hypercholesterolemia. Statins had no effect on post-CEA restenosis.

\section{Acknowledgment}

The authors acknowledge Mona Lett for assistance in organizing and proofreading this manuscript.

\section{REFERENCES}

1. Samson RH. The role of statin drugs in the management of the peripheral vascular patient. Vasc Endovascular Surg. 2008; 42:352-366. [PubMed: 18621887]

2. Kennedy J, Quan H, Buchan AM, et al. Statins are associated with better outcomes after carotid endarterectomy in symptomatic patients. Stroke. 2005; 36:2072-2076. [PubMed: 16179564]

3. Vaughan CJ, Delanty N. Neuroprotective properties of statins in cerebral ischemia and stroke. Stroke. 1999; 30:1969-1973. [PubMed: 10471452]

4. Sillesen H. What does "best medical therapy" really mean? Eur J Vasc Endovasc Surg. 2008; 35:139-144. [PubMed: 18160316] 
5. Perler B. The effect of statin medications on perioperative and long term outcomes following carotid endarterectomy or stenting. Semin Vasc Surg. 2007; 20:252-258. [PubMed: 18082842]

6. Shepherd S, Cobbe SM, Ford I, et al. Prevention of coronary heart disease with pravastatin in men with hypercholesterolemia. N Engl J Med. 1995; 333:1301-1307. [PubMed: 7566020]

7. Scandinavian simvastatin survival group: randomized trial of cholesterol lowering in 4,444 patients with coronary heart disease: the Scandinavian Survival Study (4S). Lancet. 1994; 344:1383-1389. [PubMed: 7968073]

8. Heart protection study collaborative group: the MRC/BHF Heart Protection Study of cholesterol lowering with simvastatin in 20,536 high risk individuals: atomized placebo-controlled trial. Lancet. 2002; 360:7-22. [PubMed: 12114036]

9. AbuRahma AF, Stone PA, Deem S, et al. Proposed duplex velocity criteria for carotid restenosis following carotid endarterectomy with patch closure. J Vasc Surg. 2009; 50:286-291. [PubMed: 19631861]

10. Sacks FM, Pfeffer MA, Moye LA, et al. The effect of pravastatin on coronary events after myocardial infarction in patients with average cholesterol levels. N Engl J Med. 1996; 335:10011009. [PubMed: 8801446]

11. Xu Y, Zhou S, Fang Z, et al. Inhibition of neointimal hyperplasia in rats treated with atorvastatin after carotid surgery may be mainly associated with down-regulation of surviving and Fas expression. Pharm Biol. 2014; 52:1196-1203. [PubMed: 25116077]

12. Nemoto M, Hoshina K, Takayama T, et al. Statins reduce extensive aortic atheromas in patients with abdominal aortic aneurysms. Ann Vasc Dis. 2013; 6:711-717. [PubMed: 24386020]

13. Fang SY, Roan JN, Luo CY, et al. Pleiotropic vascular protective effects of statins in perioperative medicine. Acta Anaesthesiologica Taiwanica. 2013; 51:120-126. [PubMed: 24148741]

14. Tentzeris I, Rohla M, Jarai R, et al. Influence of high-dose highly efficient statins on short-term mortality in patients undergoing percutaneous intervention with stenting for acute coronary syndrome. Am J Cardiol. 2014; 113:1099-1104. [PubMed: 24462073]

15. Schwartz GG, Olsson AG, Ezekowitz MD, et al. Effects of atorvastatin on early recurrent ischemic events in acute coronary syndromes: the MIRACL study: a randomized controlled trial. JAMA. 2001; 285:1711-1718. [PubMed: 11277825]

16. Cannon $\mathrm{CP}$, Braunwald $\mathrm{E}, \mathrm{McCabe} \mathrm{CH}$, et al. Intensive versus moderate lipid lowering with statins after acute coronary syndromes. N Engl J Med. 2004; 350:1495-1504. [PubMed: 15007110]

17. DeMartino RR, Eldrup-Jorgenson J, Nolan BW, et al. Perioperative management with antiplatelet and statin medication is associated with reduced mortality following vascular surgery. $\mathrm{J}$ Vasc Surg. 2014; 59:1615-1621. [PubMed: 24439325]

18. Ward RP, Leeper NI, Kirkpatrick JN, et al. The effect of peri-operative statin therapy on cardiovascular outcomes in patients undergoing infrainguinal vascular surgery. Int J Cardiol. 2005; 104:264-268. [PubMed: 16186054]

19. deBruin JL, Baas AF, Heymans MW, et al. Statin therapy is associated with improved survival after endovascular and open aneurysm repair. J Vasc Surg. 2014; 59:39-44. [PubMed: 24144736]

20. Westin GG, Armstrong EJ, Bang H, et al. Association between statin medication and mortality, major adverse cardiovascular event, and amputation-free survival in patients with critical limb ischemia. J Am Coll Cardiol. 2014; 63:682-690. [PubMed: 24315911]

21. Aiello FA, Khan AA, Meltzer AI, et al. Statin therapy is associated with superior clinical outcomes after endovascular treatment of critical limb ischemia. J Vasc Surg. 2012; 55:371-379. [PubMed: 22051864]

22. Vogel TR, Dombrovskiy VY, Galinanes EL, Kruse RL. Perioperative statins and limb salvage after lower extremity revascularization in the Medicare population. Circ Cardiovasc Interv. 2013; 6:694-700. [PubMed: 24300135]

23. Suckow BD, Kraiss LW, Schanzer A, et al. Statin therapy after infrainguinal bypass surgery for critical limb ischemia is associated with improved 5-year survival. J Vasc Surg. Jul 16. [Epub ahead of print].

24. Dosluoglu HH, Davari-Farid S, Pourafkari L, et al. Statin use is associated with improved overall survival without affecting patency and limb salvage rates following open or endovascular revascularization. Vasc Med. 2014; 19:86-93. [PubMed: 24829310] 
25. Sanders RD, Nicholson A, Lewis SR, et al. Perioperative statin therapy for improving outcomes during and after noncardiac vascular surgery. Cochrane Database Syst Rev. Jul 3.2013 7:CD009971. http://dx.doi.org/10.1002/14651858.CD009971. pub2. [PubMed: 23824754]

26. McGirt MJ, Perler BA, Brooke BS, et al. 3-hydroxyl-3-methylglutaryl coenzyme A reductase inhibitors reduce the risk of perioperative stroke and mortality after carotid endarterectomy. $\mathrm{J}$ Vasc Surg. 2005; 42:829-836. [PubMed: 16275430]

27. LaMuraglia GM, Stoner MC, Brewster DC, et al. Determinants of carotid endarterectomy anatomic durability: Effects of serum lipids and lipid lowering drugs. J Vasc Surg. 2005; 41:762-768. [PubMed: 15886657]

28. Perler BA. Should stains be given routinely before carotid endarterectomy? Perspect Vasc Surg Endovasc Ther. 2007; 19:240-245. [PubMed: 17911547]

29. AbuRahma AF, Khan JH, Robinson PA, et al. Prospective randomized trial of carotid endarterectomy with primary closure and patch angioplasty with saphenous vein, jugular vein, and polytetrafluoroethylene: Perioperative (30-day) results. J Vasc Surg. 1996; 24:998-1007. [PubMed: 8976353]

30. AbuRahma AF, Robinson PA, Saiedy S, et al. Prospective randomized trial of carotid endarterectomy with primary closure and patch angioplasty with saphenous vein, jugular vein, and polytetrafluoroethylene: Long-term follow-up. J Vasc Surg. 1998; 27:222-234. [PubMed: 9510277]

31. Bond R, Rerkasem K, Naylor AR, et al. Systematic review of randomized controlled trials of patch angioplasty vs primary closure and different types of patch materials during carotid endarterectomy. J Vasc Surg. 2004; 40:1126-1135. [PubMed: 15622366] 


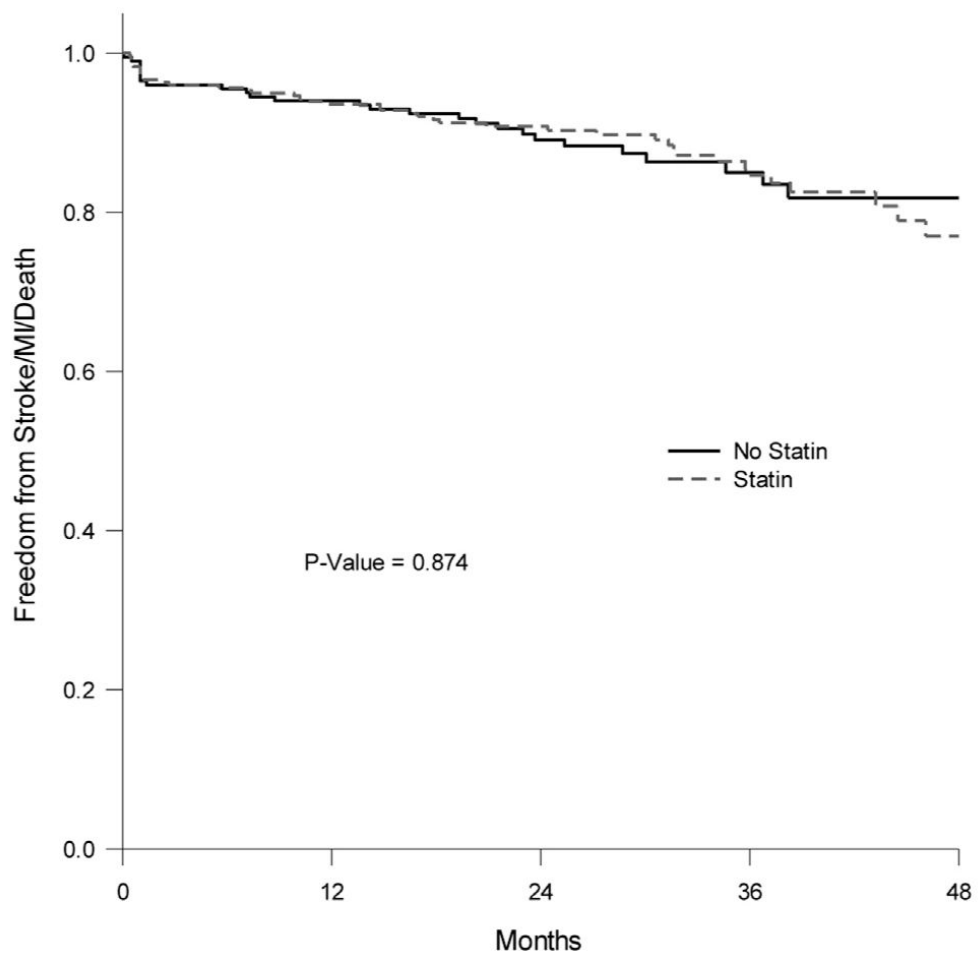

Figure 1.

Rates of freedom from stroke, MI, and death at 1,2,3, and 4 years for patients on statins vs no statins (whole group). 


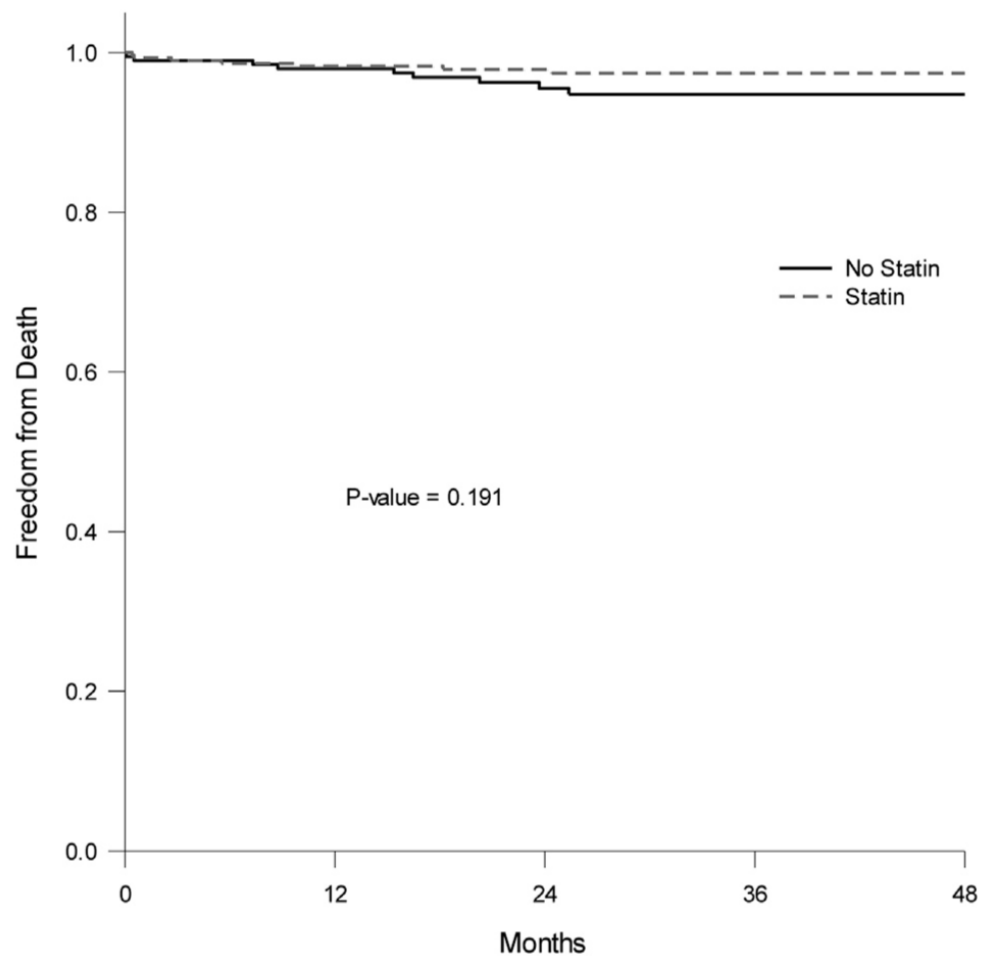

Figure 2.

Rates of freedom from death at 1,2,3, and 4 years for patients on statins vs no statins (whole group). 


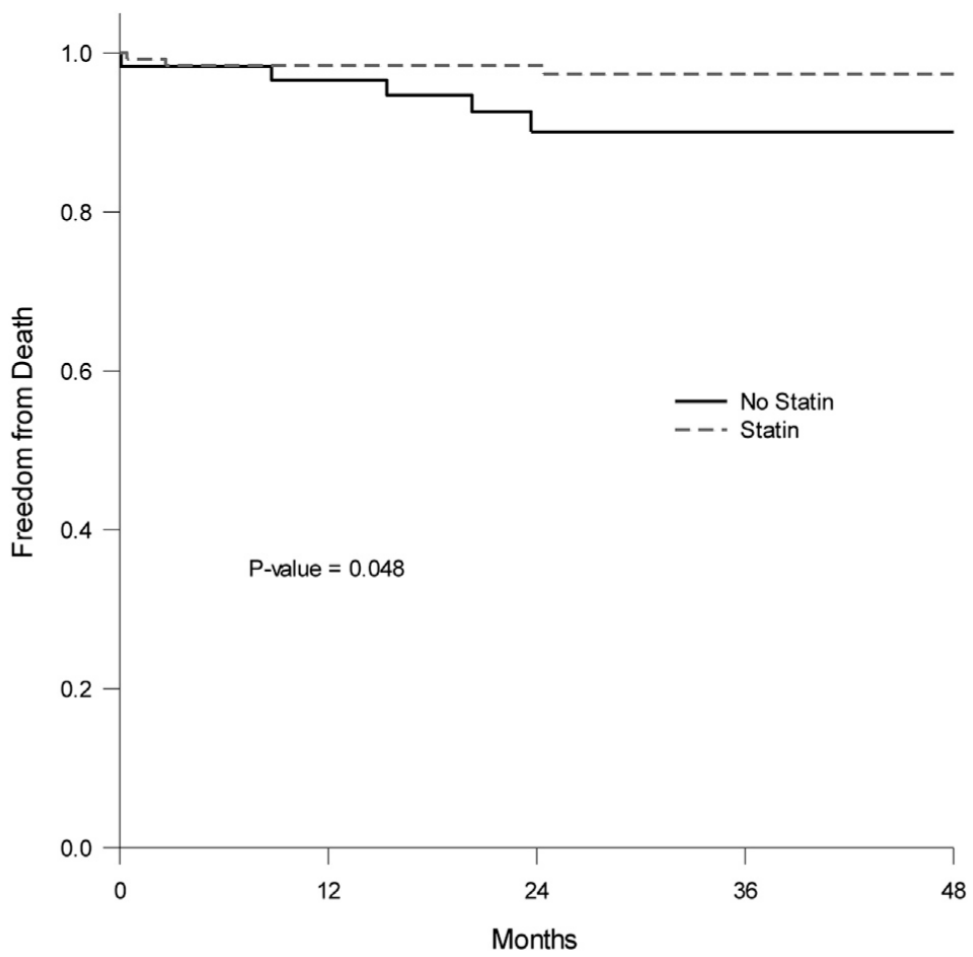

Figure 3.

Rates of freedom from death (diabetic patients only) at 1,2,3, and 4 years for patients on statins vs no statins. 


\section{Table 1}

Demographic and Clinical Characteristics

\begin{tabular}{|c|c|c|c|c|c|}
\hline \multirow[b]{2}{*}{ Characteristic } & \multicolumn{2}{|c|}{$\begin{array}{r}\text { No statins } \\
(\mathrm{n}=\mathbf{2 0 1}) \\
\end{array}$} & \multicolumn{2}{|c|}{$\begin{array}{r}\text { Statins } \\
(\mathbf{n}= \\
\mathbf{2 9 9}) \\
\end{array}$} & \multirow[b]{2}{*}{ p Value } \\
\hline & $\mathbf{n}$ & $\%$ & $\mathbf{n}$ & $\%$ & \\
\hline Sex, male & 111 & 55 & 154 & 52 & 0.414 \\
\hline Race, white & 199 & 99 & 295 & 99 & 1 \\
\hline Hypertension & 161 & 80 & 252 & 84 & 0.2266 \\
\hline History of stroke & 35 & 17 & 41 & 14 & 0.2585 \\
\hline Coronary artery disease & 76 & 38 & 128 & 43 & 0.2648 \\
\hline Hyperlipidemia & 116 & 58 & 228 & 76 & $<0.0001$ \\
\hline Diabetes mellitus & 59 & 29 & 131 & 44 & 0.0011 \\
\hline Chronic renal insufficiency & 24 & 12 & 31 & 10 & 0.5817 \\
\hline COPD & 45 & 22 & 63 & 21 & 0.7255 \\
\hline Current smoker & 74 & 37 & 97 & 32 & 0.312 \\
\hline Previous smoker & 47 & 23 & 68 & 23 & 0.8675 \\
\hline All smokers & 121 & 60 & 165 & 55 & 0.2665 \\
\hline
\end{tabular}

$J$ Am Coll Surg. Author manuscript; available in PMC 2016 April 01. 


\section{Table 2}

Early Perioperative and Late Outcomes

\begin{tabular}{|c|c|c|c|c|c|c|}
\hline \multirow[b]{2}{*}{ Outcomes } & \multicolumn{2}{|c|}{$\begin{array}{r}\text { No statins } \\
(\mathrm{n}=\mathbf{2 0 1}) \\
\end{array}$} & \multicolumn{2}{|c|}{$\begin{array}{c}\text { Statins, } \\
(\mathbf{n}=299) \\
\end{array}$} & \multirow{2}{*}{$\begin{array}{c}\text { Total, } \\
\mathbf{n}\end{array}$} & \multirow{2}{*}{$\mathbf{p}_{\text {Value }}$} \\
\hline & $\mathbf{n}$ & $\%$ & $\mathbf{n}$ & $\%$ & & \\
\hline \multicolumn{7}{|l|}{ Perioperative outcomes } \\
\hline Perioperative stroke & 4 & 2 & 5 & 1.7 & 9 & 1 \\
\hline Perioperative MI & 5 & 2.5 & 6 & 2 & 11 & 0.7619 \\
\hline Perioperative death & 3 & 1.5 & 3 & 1 & 6 & 0.6885 \\
\hline $\begin{array}{l}\text { Perioperative stroke/ } \\
\text { death }\end{array}$ & 5 & 2.5 & 7 & 2.3 & 12 & 1 \\
\hline MI/death & 8 & 4 & 8 & 2.7 & 16 & 0.4164 \\
\hline $\begin{array}{l}\text { Perioperative MI/ } \\
\text { stroke/death }\end{array}$ & 10 & 5 & 12 & 4 & 22 & 0.6072 \\
\hline \multicolumn{7}{|l|}{$\begin{array}{c}\text { Combined early and } \\
\text { late outcomes }\end{array}$} \\
\hline Stroke & 5 & 2.5 & 7 & 2.3 & 12 & 1 \\
\hline MI & 18 & 9 & 29 & 9.7 & 47 & 0.7799 \\
\hline Death & 9 & 4.5 & 7 & 2.3 & 16 & 0.1832 \\
\hline Stroke/death & 12 & 6 & 13 & 4.3 & 25 & 0.4144 \\
\hline MI/death & 25 & 12.4 & 35 & 11.7 & 60 & 0.8049 \\
\hline $\mathrm{MI} /$ stroke/death & 27 & 13.4 & 40 & 13.4 & 67 & 0.9859 \\
\hline
\end{tabular}


Table 3

Early and Late Outcomes in Patients with Diabetes Mellitus

\begin{tabular}{lcrrrrr}
\hline & $\begin{array}{c}\text { No statins } \\
(\mathbf{n = 5 9 )}\end{array}$ & \multicolumn{3}{c}{$\begin{array}{c}\text { Statins } \\
\text { Outcomes }(\mathbf{n}=\mathbf{1 3 1})\end{array}$} & \\
\cline { 2 - 5 } & $\mathbf{n}$ & $\%$ & $\mathbf{n}$ & $\%$ & $\mathbf{p ~ V a l u e}$ \\
\hline Death & 5 & 8.5 & 3 & 2.3 & 0.1101 \\
\hline Stroke & 2 & 3.4 & 5 & 3.8 & 1 \\
\hline MI & 7 & 11.9 & 17 & 13 & 0.8308 \\
\hline Stroke/death & 6 & 10.2 & 7 & 5.3 & 0.229 \\
\hline MI/stroke/death & 12 & 20.3 & 22 & 16.8 & 0.5553 \\
\hline MI/death & 11 & 18.7 & 19 & 14.5 & 0.469 \\
\hline
\end{tabular}




\section{Table 4}

Early and Late Outcomes in Patients with Hypercholesterolemia

\begin{tabular}{lccl}
\hline Outcomes $(\mathbf{n}=\mathbf{3 4 4})$ & $\begin{array}{c}\text { No statins, } \\
\mathbf{n}(\boldsymbol{\%}) \\
(\mathbf{n}=\mathbf{1 1 6})\end{array}$ & $\begin{array}{c}\text { Statins, } \\
\mathbf{n}(\mathbf{\%}) \\
(\mathbf{n = 2 2 8})\end{array}$ & p Value \\
\hline Death & $5(4.3)$ & $5(2.2)$ & 0.3144 \\
\hline Stroke & $2(1.7)$ & $4(1.8)$ & 1 \\
\hline MI & $14(12.1)$ & $20(8.8)$ & 0.3327 \\
\hline Stroke/death & $6(5.2)$ & $9(4)$ & 0.5989 \\
\hline MI/stroke/death & $18(15.5)$ & $28(12.3)$ & 0.4044 \\
\hline MI/death & $17(14.7)$ & $25(11)$ & 0.323 \\
\hline
\end{tabular}

